\title{
On the creep fatigue and creep rupture behaviours of 9-12\% Cr steam turbine
} rotor

\author{
Xuanchen Zhu ${ }^{1}$, Haofeng Chen ${ }^{1,2, *}$, Fuzhen Xuan ${ }^{2}$, Xiaohui Chen ${ }^{3}$ \\ ${ }^{1}$ Department of Mechanical \& Aerospace Engineering, University of Strathclyde, G1 1XJ, UK \\ ${ }^{2}$ School of Mechanical and Power Engineering, East China University of Science and Technology, 200237, \\ China \\ ${ }^{3}$ School of Control Engineering, Northeastern University, Qinhuangdao, 066004, China.
}

\begin{abstract}
This paper presents the study of creep-fatigue interaction damage and creep rupture limit for 9-12\% Cr steam turbine rotor under coupled cyclic thermal-mechanical loadings that alter in phase and out of phase. The investigation is implemented using the Linear Matching Method (LMM) and based on the newly developed creep-fatigue and creep rupture evaluation procedures. Latest experimental creep data of FB2 which belongs to 9-12\% Cr heat-resistant steel family is employed to calculate creep-related damage and creep rupture bearing capacity of steam turbine rotor. Various factors that affect creep and fatigue damage of steam turbine rotor are analyzed and discussed, including dwell period and rotating speed of rotor. From the parametric studies, the damage locations and cycles to failure induced by creep and fatigue mechanism are presented respectively. Moreover, through creep rupture analyses for varying desired fracture time, the novel creep rupture curves under multi-type double-cyclic-loading conditions are given and further compared with cyclic plasticity failure curve. These surrogate-model analyses offer a deep understanding of structural responses of steam turbine rotor under long-term high temperature operation and provide critical loading conditions to be referenced for smooth running.
\end{abstract}

Keywords: Creep damage, Fatigue damage, Creep rupture, Steam turbine rotor, Linear Matching Method

\section{Introduction}

As one of the most critical components in a set of power generation plants, considerable efforts have been put in to ensure the safe operation of the steam turbine rotor. For instance, a host of structural optimization designs have been proposed by many researchers [1, 2, 3]. And recently, the high chromium steel in 9-12\% Cr heatresistant steel family are widely used in a variety of rotors due to its excellent heat properties, corrosion resistance, superior molding property to be processed and so on [4,5]. Nevertheless, practical engineering experience has indicated that, during the long-term high-temperature service life of steam turbine rotor subjected to complicated cyclic loading, effects caused by creep could greatly weaken the performance of materials and

* Corresponding author.

Email: haofeng.chen@strath.ac.uk

Tel: +44(0) 1415482036 
the devices, then further lead to catastrophic plastic and creep failure. Therefore, investigating creep behaviors is of a priority importance for long-term integrity assessments and design of steam turbine rotor.

For structures operating under high temperature and cyclic loading history, the creep and fatigue are competing mechanisms relying on the strain range and dwell time [6, 7, 8]. Hales defined four cases of interaction in [9], which is then extended by Plumbridge [10]. The first case is a Pure Fatigue process, where the surface cracking is critical. The second case is Transgranular Competing, at which the transgranular crack is produced during the tensile hold time. The third case involves Mixed Interaction behaviour, in which the transgranular cracking converted into intergranular. The last case is Pure Creep, where the loading cycle is allowed to be considered as a monotonic load case due to long enough hold time. In order to investigate the creep-fatigue interaction effects and the resulted combined damage, a mass of damage models [11, 12, 13] have been proposed by many scholars. But in industrial applications, the common lack of availability of data makes it not easily accessible to fit the numerous constants in the constitutive models. Hence, for analyses considering creep, when the constitutive equations applied for assessing creep damage process require numerous constants or damage induced by creep grows dramatically, it is necessary to employ the creep-rupture-data-based methods [14] to accurately analyze the creep-related phenomenon with fewer constants. In these approaches, the creep strain under the loading history is not essential to be calculated, thus the difficulties of applying detailed creep constitutive models could be avoided. Therefore, these creep-rupture-data-based methods are employed in this study to investigate the creep-related structural responses of rotor.

The responses of steam turbine rotor under complex loading conditions with the consideration of creep effect have been investigated by a number of researchers [15, 16, 17], especially for creep-fatigue interaction and creep rupture behavior under high temperature. In most cases, full step-by-step Finite Element Analysis (FEA) was employed for simulation and modeling, and further fitted with experimental results. In fact, FEA with direct analysis methods are also capable of comprehensively modeling the structural features and material behaviors under high-temperature cyclic loading histories, which can not only provide the accurate results but also calculate the stabilized state response of structures with far less computational efforts. The Linear Matching Method (LMM), as a Direct Method, is distinguished from the other simplified methods as both the equilibrium and compatibility can be satisfied at each stage $[18,19]$. Recently, this method has been much optimized for performing the structural integrity assessment involving high-temperature creep effect. LMM Direct Steady Cycle Analysis (DSCA) was extended to assess creep-fatigue interaction and verified by Refs. [20, 21]. Shakedown Analysis of the LMM was enriched to evaluate creep rupture limit by imposing the revised yield stress and Refs. [22, 23] give the demonstration. But there is no application by integrally using the improved approaches to analyze complicated practical structures subjected to coupled cyclic thermal-mechanical loads. Therefore, in this paper, the latest developed LMM is adopted to assess the steady state cycle response of the steam turbine rotor manufactured by FB2 heat-resistant steel, which is subjected to the coupled cyclic thermalmechanical loading with a creep dwell at steady operation phase. Dwell time and rotating speed which affect creep and fatigue behaviors of steam turbine rotor are investigated. Creep rupture analyses of the structure are also performed through using the extension of the LMM framework, and the innovative creep rupture curves under double-cyclic-loading are further proposed by calculating different combinations of cyclic thermalmechanical load. 


\section{Theoretical Background}

We consider an isotropic elastic and perfectly plastic body, which is subjected to a general cyclic loading condition and satisfies the von-Mises yield condition. The body is assumed to have a volume $\mathrm{V}$ in which a cyclic history of varying temperature $\lambda_{\theta} \theta(x, t)$ and varying centrifugal force $\lambda_{c} C(x, t)$ are applied alongside a cyclic history of varying surface load $\lambda_{p} P(x, t)$ acting on part of the structure's surface $S_{T}$. Introducing the load parameter $\lambda$ here makes analyzing an entire class of loading histories be possible. The remaining part of the surface $S$, denoted as $S_{u}$, is restrained to have a zero displacement $u=0$. A typical cycle is considered to occur between $0 \leq t \leq \Delta t$.

The applied cyclic load history and corresponding linear elastic solution can be represented as follow:

$$
\begin{gathered}
F(x, t)=\lambda_{\theta} \theta(x, t)+\lambda_{c} C(x, t)+\lambda_{p} P(x, t) \\
\hat{\sigma}_{i j}(x, t)=\lambda_{\theta} \hat{\sigma}_{i j}^{\theta}(x, t)+\lambda_{f} \hat{\sigma}_{i j}^{F}(x, t)+\lambda_{P} \hat{\sigma}_{i j}^{P}(x, t)
\end{gathered}
$$

As for a cyclic problem, the cyclic stress history is expressed by

$$
\sigma_{i j}(x, t)=\lambda \hat{\sigma}_{i j}(x, t)+\bar{\rho}_{i j}(x)+\rho_{i j}^{r}(x, t)
$$

where $\lambda \hat{\sigma}_{i j}(x, t)$ is the elastic solution, $\bar{\rho}_{i j}(x)$ is the constant residual stress field in equilibrium with zero surface traction on $S_{T}$ and corresponds to the residual state of stress at the beginning and end of the cycle, $\rho_{i j}^{r}(x, t)$ is the change in residual stress during the cycle which satisfies

$$
\rho_{i j}^{r}(x, 0)=\rho_{i j}^{r}(x, \Delta t)
$$

\subsection{An extended LMM Direct Steady Cycle Analysis considering creep effect}

We apply an extended LMM Direct Steady Cycle Analysis (DSCA) in this work to assess the low cycle fatigue behavior with the consideration of creep effect, which is to obtain cyclic stress history under steady state with the accumulated residual stress field caused by either creep or plastic behaviors. The extended DSCA approach includes a suite of iterative cycles which could be defined as $m=1,2 \ldots \mathrm{M}$. Each iterative cycle is based on a series of increments $N$, which is corresponded with the number of time points in one cycle from $n=1,2 \ldots N$. Through an iterative way, the extended DSCA procedure can evaluate each individual varying residual stress $\Delta \rho_{i j}^{r}\left(x, t_{n}\right)_{m}$ attached with each elastic solution $\hat{\sigma}_{i j}\left(x, t_{n}\right)_{m}$. For coming up to a converged solution, the constant residual stress in equation can be given as

$$
\bar{\rho}_{i j}(x)=\sum_{m=1}^{M} \sum_{n=1}^{N} \Delta \rho_{i j}^{r}\left(x, t_{n}\right)_{m}
$$

The accumulated residual stress of $n$th load instance at $m$ th cycle of iterations can be determined by 


$$
\rho_{i j}^{r}\left(x, t_{n}\right)_{m}=\sum_{k=1}^{m-1} \sum_{n=1}^{N} \Delta \rho_{i j}^{r}\left(x, t_{n}\right)_{k}+\sum_{k=1}^{n} \Delta \rho_{i j}^{r}\left(x, t_{k}\right)_{m}
$$

Ref [24] gives the detailed description of the evaluation of the residual stress $\Delta \rho_{i j}^{r}(x, t)$ at each increment resorting to the solution of a formulated linear problem. Through the procedure, we can acquire the residual stress field, and the iterative shear modulus $\bar{\mu}\left(x, t_{n}\right)_{m}$ is available to be renovated for each cycle at each load instance $t_{n}$ corresponding to the following linear matching formula

$$
\bar{\mu}\left(x, t_{n}\right)_{m+1}=\bar{\mu}\left(x, t_{n}\right)_{m} \frac{\sigma_{y}^{R}\left(x, t_{n}\right)_{m}}{\bar{\sigma}\left(\widehat{\sigma}_{i j}\left(x, t_{n}\right)_{m}+\rho_{i j}^{r}\left(x, t_{n}\right)_{m}\right)}
$$

where $\bar{\mu}\left(x, t_{n}\right)_{m}$ is the iterative shear modulus for $n$th load instance at $m$ th cycle. $\sigma_{y}^{R}\left(x, t_{n}\right)_{m}$ is the yield stress of Elastic-Perfectly-Plastic model at load instance $t_{n}$, which will be substituted by creep flow stress when creep relaxation occurs at a load instance. Convergence will be estimated after one single cycle, a subsequent cycle will start or all the key parameters will be outputted for the following creep-fatigue damage analysis if the convergence standard is met.

\subsection{An extended LMM shakedown analysis for creep rupture assessment}

The linear matching method to creep rupture analysis can be regarded as an extended shakedown analysis by using the revised yield stress, which is determined by the minimum of the yield stress of the material and the individual creep rupture stress at integration point. For a given time to rupture $t_{f}$, the creep rupture stress is related with the applied temperature $T$. Chen et al. [25] proposed an analytical formulation for calculating the creep rupture stress without directly using experimental data, which is determined by the yield stress of material and two analytical functions as given below:

$$
\sigma_{c}\left(x_{i}, t_{f}, T\right)=\sigma_{y} \cdot R\left(\frac{t_{f}}{t_{0}}\right) \cdot g\left(\frac{T}{T_{0}}\right)
$$

where $X_{i}$ represents the position of integration point, $t_{0}$ and $T_{0}$ are material constants, $R\left(t_{f} / t_{0}\right)$ is the function of a given creep rupture time $t_{f}$ and $g\left(T / T_{0}\right)$ is the function of the applied temperature $T$. What deserves attention is that it is unpractical to obtain a unique equation of creep rupture stress for some kind of materials. Therefore, chen et al. [25] proposed an optimized approach for a particular case of holed plate, where the function of $R\left(t_{f} / t_{0}\right)$ was set as a known parameter and the function of applied temperature $g\left(T / T_{0}\right)$ was formulated as:

$$
g\left(\frac{T}{T_{0}}\right)=\frac{T_{0}}{T-T_{0}}
$$

It is worth noting that it would be extremely hard to formulate equation (8) in practical engineering applications with limited experimental creep rupture data. To solve this problem, Barbera and Chen [26] raised up a new 
numerical approach to evaluate creep rupture stress by using limited creep rupture experimental data. It is accessible to apply an extended shakedown procedure for creep rupture analysis once the revised yield stress is available from the creep rupture stress for a given creep rupture time and temperature. In this new approach, how to interpolate and extrapolate the limited creep rupture experimental data is the main challenging issue, on which many other scholars[27,28,29,30,31] have done much to obtain reliable long term creep rupture data. To overcome it, Barbera and Chen [26] contrasted three strategies (linear interpolation, logarithmic approach and Larson-Miller approach), and these three methods were implemented in the solution processing and extrapolating Nimonic 80-A creep rupture data. In most cases, the results showed that Larson-Miller approach was the best option to provide accurate predictions than the other two methods. Through ABAQUS user subroutine UMAT [32], these mentioned methods are installed via a FORTRAN subroutine named the LMM creep rupture analysis, and where the Larson-Miller method is set as the default method to evaluate creep rupture stress, but the other two approach are also available for the user.

\section{Problem Description}

\subsection{Geometric and finite element model}

Fig.1 (a) exhibits the holistic structure model of targeted rotor. Plane condition as shown in Fig.1 (b) is employed to model the effects of adjacent rotor wheels, and cyclic symmetry condition as shown in Fig.1 (b) is applied to simulate $1 / 91$ section of a $360^{\circ}$ cyclic periodic rotor wheel. These constraints enable 1/91 section of a rotor wheel to be established in ABAQUS to analyse the creep related structural response of rotor under cyclic thermal-mechanical load with applying the extended LMM. In addition, the cyclic plasticity behaviours of this model without the consideration of creep effect have also been investigated in Ref [33].

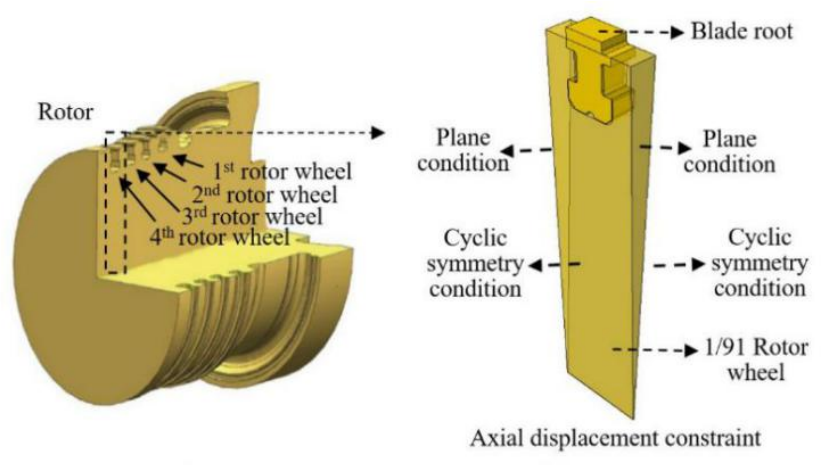

(a)

(b)

Fig.1. (a) Holistic structure model of rotor, (b) 1/91 rotor wheel with constraints

As given in Fig. 2 (a), the centrifugal forces of rotor and blade during cyclic start-up, running, shut down operation make the structure suffer cyclic mechanical load. Fig. 2 (b) displays the detailed cyclic mechanical loads acting on the rotor wheel groove which is the most vulnerable area of the rotor. The load 1 and load 2 are uniform pressures caused by blade centrifugal force, where load 1 is greater than load 2 due to the asymmetric design of blade. The load 3 represents the in-house centrifugal force of rotor wheel. Meanwhile, as exhibited in the Fig. 2 (a), high temperature steam flowing over blade root and rotor surface produces the evident temperature gradient between rotor surface and rotor root, which is further converted to cyclic thermal load of 
the structure during cyclic operational process. Fig. 2 (c) depicts the meshed 1/91 rotor wheel with blade root which are assigned with 9358 C3D20R quadratic elements

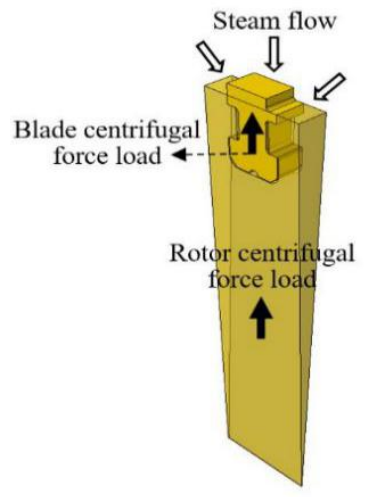

(a)

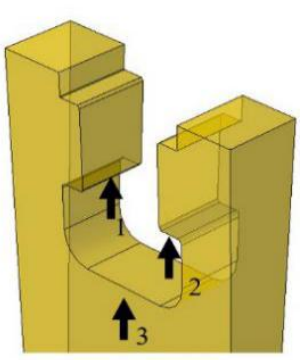

(b)

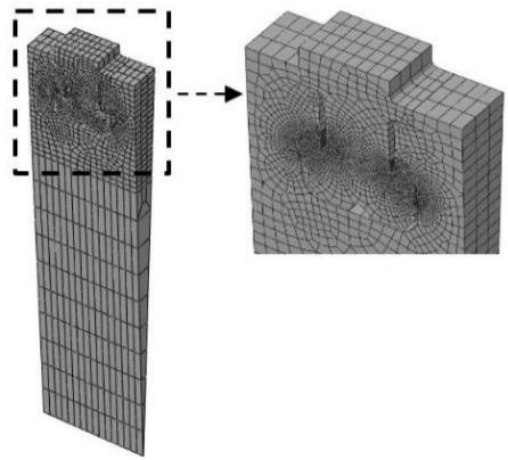

(c)

Fig.2. (a) Centrifugal forces and steam flow acting on the rotor wheel with blade root, (b) detailed mechanical loads at rotor wheel groove, (c) mesh of the rotor wheel and blade root

\subsection{Material properties}

FB2 heat-resistant steel is adopted for steam turbine rotor and blade root in this paper, which is widely applied for manufacturing the thermal power plants in recent years due to its well mechanical properties under high temperature condition, including outstanding creep strength, better resistance to steam oxidation and improved forging performance. Table 1 gives thermal-mechanical material properties of FB2 steel analyzed in this paper.

Table 1 Mechanical-thermal material properties of FB2.

\begin{tabular}{ll}
\hline \multicolumn{2}{c}{ Mechanical material property } \\
\hline Young's Modulus [GPa] & 160 \\
Poisson's ratio & 0.3 \\
Yield stress [MPa] & 240 \\
\hline \multicolumn{1}{c}{ Thermal material property } \\
\hline Coefficient of thermal expansion & $1.2 \times 10^{-5}$ \\
Specific heat capacity [J/ $\left.\mathrm{kg}^{\circ} \mathrm{C}\right]$ & 460 \\
Thermal conductivity [30 $\left.\mathrm{w} / \mathrm{m}^{\circ} \mathrm{C}\right]$ & 30 \\
Density [g/ $\mathrm{cm}^{3}$ ] & 7.7 \\
\hline
\end{tabular}

Norton-Bailey relationship is employed for evaluating creep behaviour happened at the running phase of the load cycle and which is given as

$$
\dot{\bar{\varepsilon}}_{c}=B \cdot \bar{\sigma}^{n} \cdot t^{m}
$$

Through a series of creep rupture experiments, we obtained the creep rupture data of FB2 (unpublished work), 
which are further applied with the stress-based time fraction method for calculating creep damage induced during operation process.

$$
d_{c}=\int_{0}^{t} \frac{d t}{t_{f}(\sigma, T)}
$$

Where the rupture time is determined by extracting the average creep stress during dwell phase. The fatigue data has been obtained from the Japanese National Institution of Material Science database [34] at $600{ }^{\circ} \mathrm{C}$, as shown in Table.2, which are produced by iso-thermal low cycle fatigue tests at various strain ranges. The number of cycles for peak tensile stress to drop $25 \%$ from its initial value is set as the number of cycles to failure. The equation $d_{f}=1 / N_{0}$ is used to calculate the fatigue damage per cycle, where $N_{0}$ is the number of cycle to failure corresponding with the strain range produced by extended Direct Steady Cycle Analysis.

Table 2 Low cycle fatigue properties under $600^{\circ} \mathrm{C}$

\begin{tabular}{|c|c|c|c|c|c|c|c|}
\hline $\begin{array}{c}\text { Plastic } \\
\text { strain } \\
\text { amplitude }\end{array}$ & $\begin{array}{l}\text { failure } \\
\text { cycles }\end{array}$ & $\begin{array}{c}\text { Plastic } \\
\text { strain } \\
\text { amplitude }\end{array}$ & $\begin{array}{l}\text { failure } \\
\text { cycles }\end{array}$ & $\begin{array}{c}\text { Plastic } \\
\text { strain } \\
\text { amplitude }\end{array}$ & $\begin{array}{l}\text { failure } \\
\text { cycles }\end{array}$ & $\begin{array}{c}\text { Plastic } \\
\text { strain } \\
\text { amplitude }\end{array}$ & $\begin{array}{l}\text { failure } \\
\text { cycles }\end{array}$ \\
\hline \multicolumn{2}{|c|}{ strain rate 0.00001} & \multicolumn{2}{|c|}{ strain rate 0.0001} & \multicolumn{2}{|c|}{ strain rate 0.001} & \multicolumn{2}{|c|}{ strain rate 0.005} \\
\hline 0.082 & 345 & 0.061 & 632 & 0.0078 & 320 & 0.0083 & 377 \\
\hline 0.064 & 601 & 0.038 & 1040 & 0.006 & 558 & 0.0059 & 623 \\
\hline 0.037 & 934 & 0.025 & 1610 & 0.0045 & 1210 & 0.0036 & 1510 \\
\hline 0.025 & 1420 & 0.022 & 1580 & 0.0028 & 2210 & 0.0026 & 2320 \\
\hline 0.015 & 4160 & 0.018 & 5550 & 0.0016 & 3910 & 0.0016 & 6650 \\
\hline 0.013 & 2650 & 0.013 & 8670 & 0.0012 & 8020 & 0.0007 & 11400 \\
\hline 0.012 & 5280 & & & 0.0007 & 12200 & & \\
\hline
\end{tabular}

\subsection{Operation Conditions}

Steam turbine rotor in this paper is assumed to experience a practical operation load cycle (2880h), which includes start-up phase of $15 \mathrm{~h}$, steady running phase of $2769 \mathrm{~h}$ and shut-down phase of $96 \mathrm{~h}$. The LMM employed in the following analyses relies on the identification of a finite number of instants within the cycle to represent the entire load cycle. According to the mechanical and thermal loading history applied to steam turbine rotor, six instants are extracted to model this start-running-shut operation cycle of the structure within the LMM, including moments at halt mode, speed reaching rated status of start-up period, maximum thermal stress of startup period, stable operation status, maximum thermal stress of shut-down period and speed reaching zero of shutdown period. Detailed descriptions of these six instants are given in Ref [33]. 
The normalized rotating speed of steam turbine rotor in this load cycle is given at Fig.3, where the maximum rotating speed $\omega_{\max }$ reaches $3000 \mathrm{r} / \mathrm{min}$. As shown that, mechanical loads of six extracted instants are applied to reconstruct mechanical loading history of rotor in LMM which is denoted as $\sigma_{p 0}^{\Delta}$. The corresponding linear elastic von Mises stress of these mechanical loads are calculated and subsequently called in LMM analysis to conduct a series of iterative linear analyses, which aims to model the nonlinear plastic behaviour of the materials and represent the history of stress and inelastic strains. As mechanical loads of instant (1), (6) are zero and instants (2), (3), (4) experience the same mechanical load, Fig.3 only provides the contours of linear elastic von Mises stress of the mechanical loads of instants (2) and (5). Besides, mechanical load of instant (2) is defined as the constant mechanical reference load $\sigma_{P 0}$ in this work, which is the maximum mechanical load of the reference operation cycle.

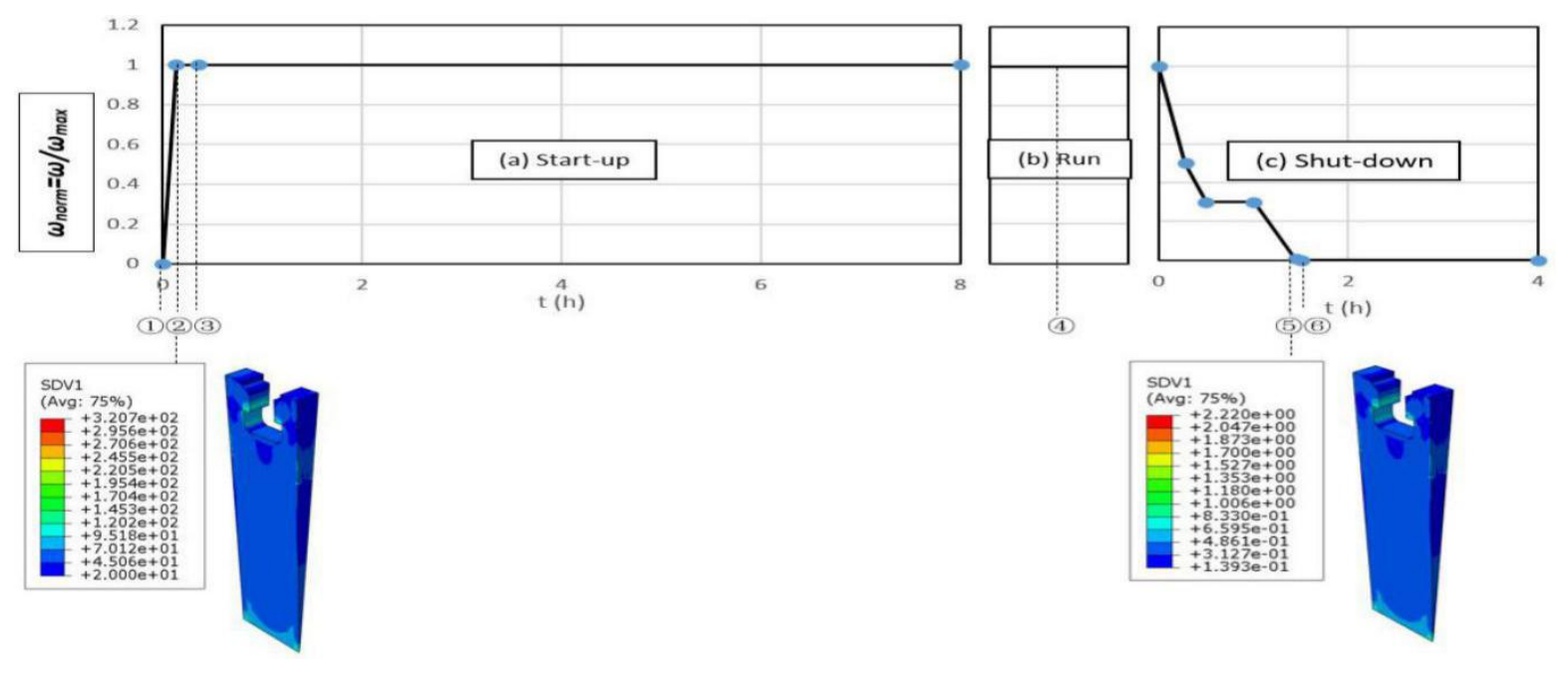

Fig.3 The normalized rotating speed curve of steam turbine rotor at practical operation load cycle and the contour of corresponding linear elastic von Mises stress

The normalized steam temperature of the practical load cycle is given in Fig.4, where the maximum steam temperature $T_{\max }$ is $600^{\circ} \mathrm{C}$. Through transient heat-transfer analysis and subsequent structural analysis, we obtain the normalized thermal stress history of the maximum location of the steam turbine rotor in Fig.5. The thermal loads of six extracted instants are used to build thermal loading history in LMM which is denoted as $\sigma_{\theta 0}^{\Delta}$. Hence, the cyclic thermal-mechanical reference load history can be defined as $\sigma_{p \theta 0}^{\Delta}=\sigma_{p 0}^{\Delta}+\sigma_{\theta 0}^{\Delta}$. Corresponding elastic von Mises stress of these thermal loads are also acquired by linear elastic analyses and given in Fig.5.
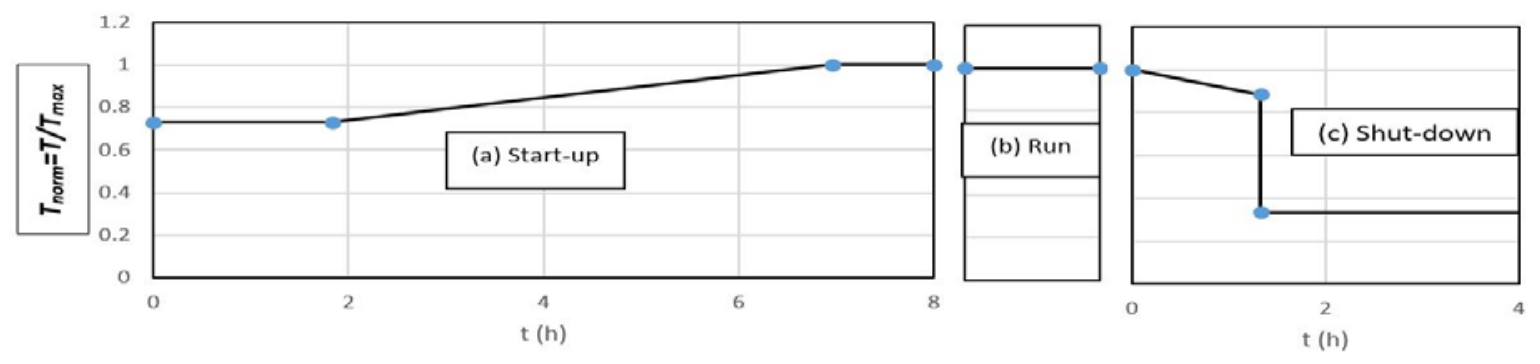

Fig.4. The normalized steam temperature curve of practical operation load cycle 


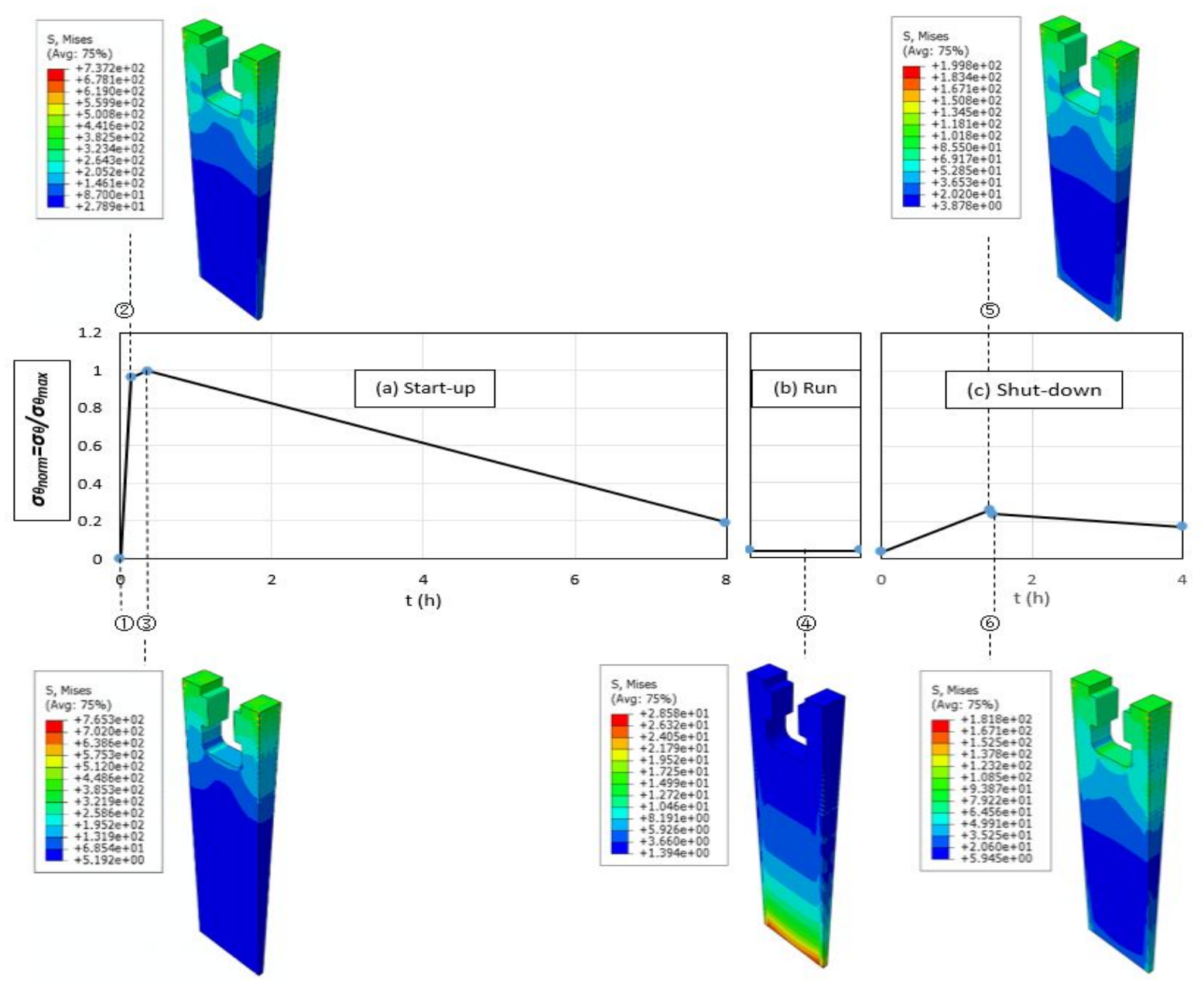

Fig.5. Normalized thermal stress history curve of steam turbine rotor during practical operation load cycle and the contour of corresponding linear elastic von Mises stress

\section{Creep-fatigue analyses}

For assessing creep-fatigue interactions and combined damages of steam turbine rotor under cyclic thermalmechanical loads, various factors that affect creep and fatigue behaviors are required to be investigated. Based on the predefined reference loading history, the influences of variation on dwell time and rotating speed to creep-fatigue damage are evaluated by using the LMM, which is capable of providing creep-fatigue damages after calculating the steady state stress-strain path of the structure under applied loading condition.

\subsection{Influence of dwell time on creep-fatigue damage}

Table.3 presents the variation of calculated dwell time based on different duration of operation cycle. We assume that the creep behaviour only happens at the steady operating phase in an operation cycle, as the start-up and shut-down phase experience relatively low temperature condition and last shorter time. For practical operating steam turbine rotor, it is inefficient and highly-costed if one operating cycle lasts too short time, therefore, we only consider the operating cycle longer than half month, where corresponding dwell time lasts $249 h$. 
Table.3 Different duration of operation cycle and corresponding creep dwell time

\begin{tabular}{llll}
\hline $\begin{array}{l}\text { Duration of operation } \\
\text { cycle (h) }\end{array}$ & $\begin{array}{l}\text { Dwell time within each } \\
\text { operation cycle (h) }\end{array}$ & $\begin{array}{l}\text { Duration of operation } \\
\text { cycle (h) }\end{array}$ & $\begin{array}{l}\text { Dwell time within each } \\
\text { operation cycle (h) }\end{array}$ \\
360 & 249 & 2520 & 2409 \\
720 & 609 & 2880 & 2769 \\
1080 & 969 & 3240 & 3129 \\
1440 & 1329 & 3600 & 3489 \\
1800 & 1689 & 3960 & 3849 \\
2160 & 2049 & 4320 & 4209 \\
\hline
\end{tabular}

Based on the predefined reference loading history, creep and fatigue damage per cycle are evaluated and plotted against dwell time in Fig.6. The observation of damage evaluation reveals that both the creep damage and fatigue damage grow linearly with the increasing of dwell time. Besides, what deserves attention is that the damage caused by creep greatly exceeds that of fatigue, and creep damage takes greater account of total damage with the growth of dwell time. For $249 \mathrm{~h}$ dwell time, creep damage takes part of $97.9 \%$ of total damage. In comparison with $4209 \mathrm{~h}$ dwell time, where creep damage contributes $99.6 \%$ to total damage, both of them make fatigue damage almost negligible. As presented in Fig.7, where x-axis represents dwell time per cycle and y-axis indicates the number of cycles to failure, it can be seen directly that the failure of the component exposed to long operation cycle is primarily dominated by creep behaviour. For predefined reference loading history, where dwell time lasts 2769h, local elements would start failing after 38 cycles, which is induced by creep-fatigue interactions, with a predicted life of 41 and 6792 cycles for creep and fatigue, respectively.

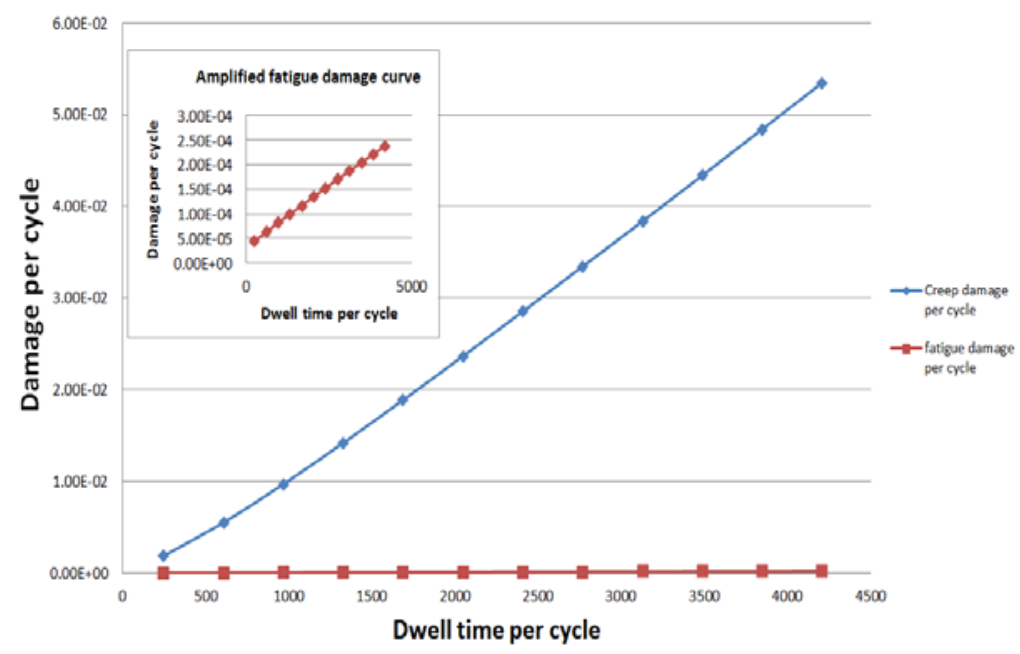

Fig.6 Creep and fatigue damage per cycle at the riskiest location against dwell time per cycle 


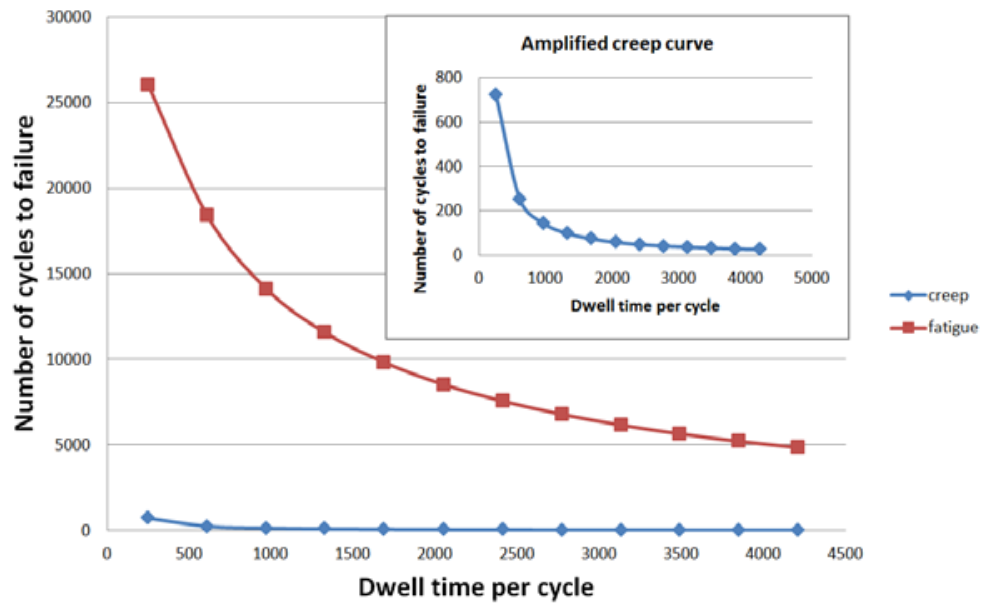

Fig.7. Number of cycles to failure due to creep and fatigue against dwell time per cycle

Fig.8 to Fig.10 show the failure locations of the structure under 249h, 2769h and 4209h dwell time, respectively. In general, creep damage happens at the significant mechanical stress concentration region in relatively local range. This is because that at the state of steady operating phase where creep occurs, the integral structure has relatively uniform temperature, cyclic mechanical load component therefore works as the main part to the current loading condition than cyclic thermal load component. For fatigue behavior caused by the combination of cyclic thermal load, the corresponding damage emerges in the global range. But with the growth of dwell time from $249 \mathrm{~h}$ to $4209 \mathrm{~h}$, fatigue damages at local groove locations gradually exceed other locations. When it goes to total damage, failure locations almost coincide with that of creep damage due to creep damage is the dominant failure mechanism.

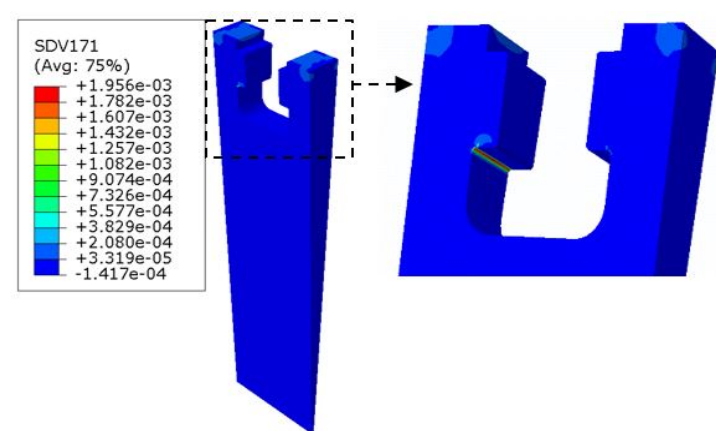

(a)

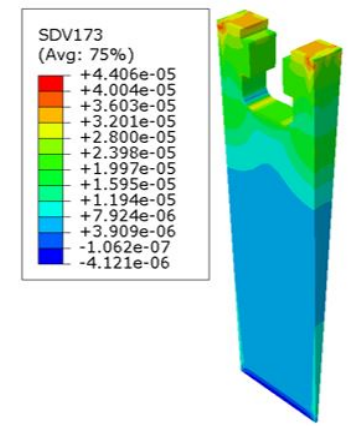

(b)

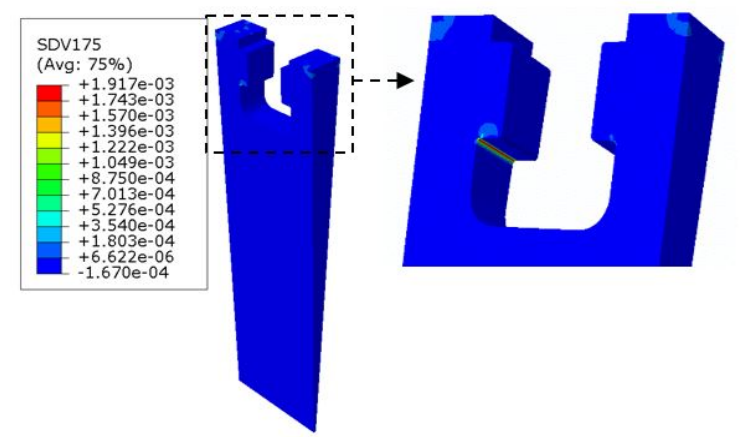

(c)

Fig.8 Contours of failure locations caused by (a) creep damage (b) fatigue damage (c) total damage under 249h dwell time 


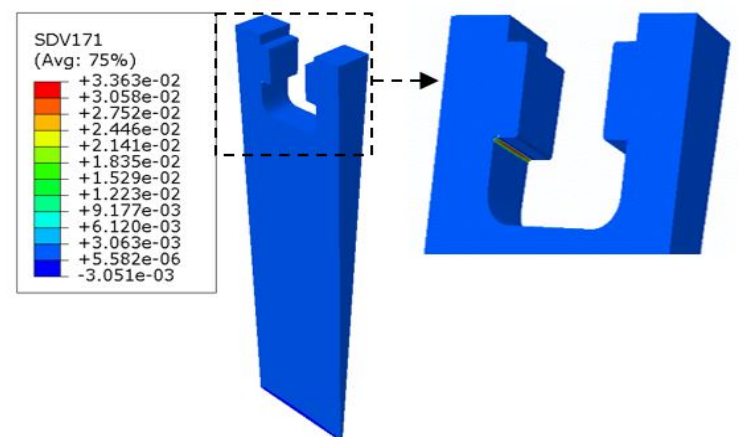

(a)

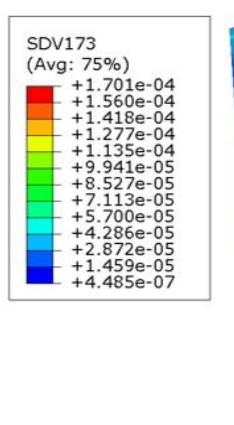

(b)
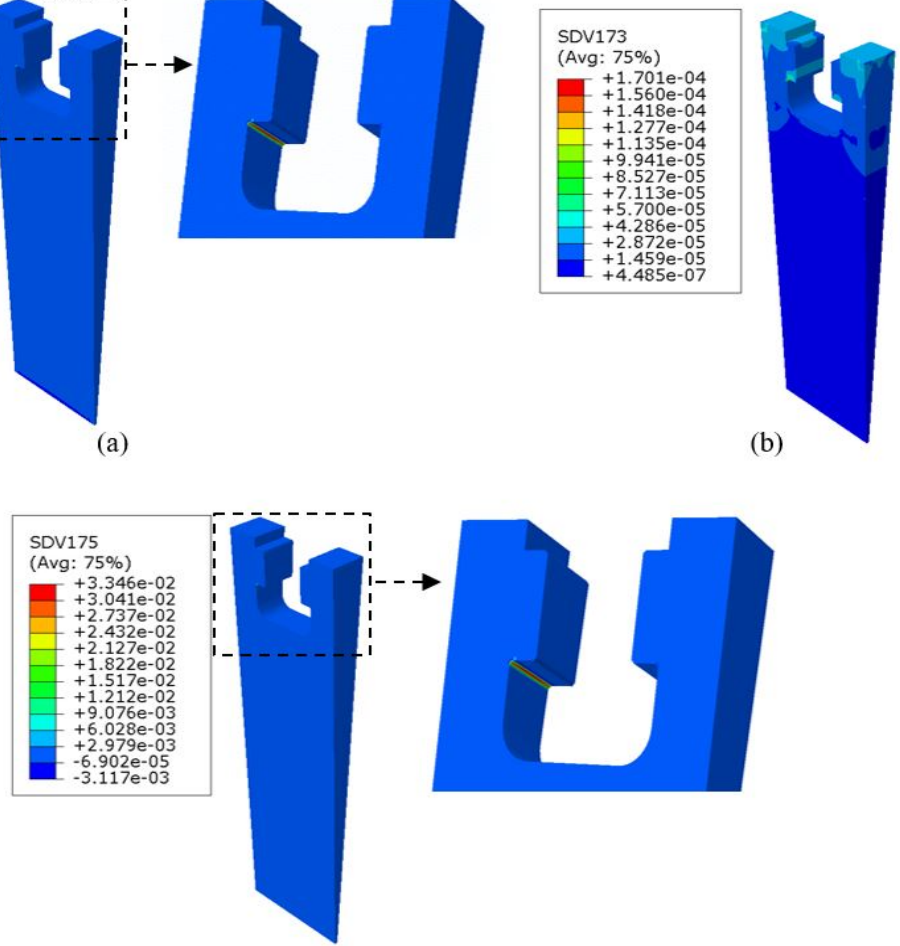

(c)

Fig.9. Contours of failure locations caused by (a) creep damage (b) fatigue damage (c) total damage under 2769h dwell time

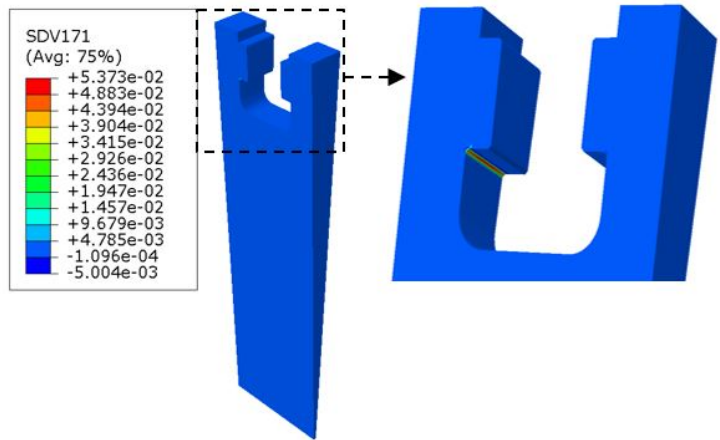

(a)

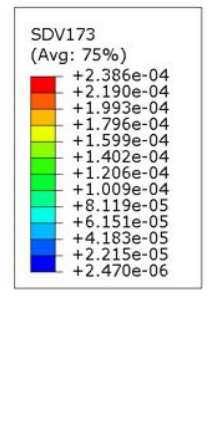

(b)

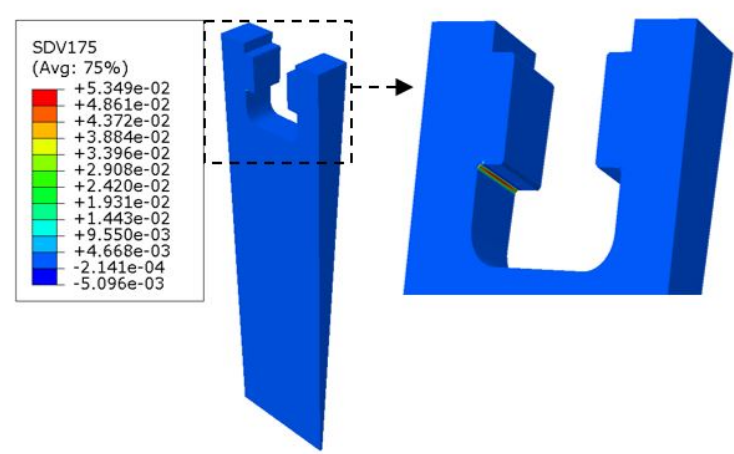

(c)

Fig.10 Contours of failure locations caused by (a) creep damage (b) fatigue damage (c) total damage under 4209h dwell time 


\subsection{Influence of rotating speed on creep-fatigue damage}

What we observe from the effect of dwell time on creep-fatigue damage is that creep damage dominates the failure for current structure subjected to predefined reference loading history. Based on the assumption in section 4.1, the creep only occurs during the running phase, at where the thermal stress produced by temperature gradient and thermal expansion gradually approaches to lower level, and mechanical stress generated by rotor rotation turns to be the primary factor affecting stress-related creep. Therefore, rotor speed is the key parameter to failure behaviour, and we now turn our attention to the structural responses under different rotating speed with dwell time of $2769 \mathrm{~h}$.

We plot the variations of creep and fatigue damage per cycle with the changing rotating speed in Fig.11, where the non-dimensional value of $\mathrm{X}$-coordinate represents the ratio of the applied cyclic mechanical stress with the reference cyclic mechanical stress and $\frac{\sigma_{p}^{\Delta}}{\sigma_{p 0}^{\Delta}}=1$ corresponds to the predefined operation mechanical load. For steam turbine rotor subjected to predefined loading history, $\frac{\sigma_{p}^{\Delta}}{\sigma_{p 0}^{\Delta}}=0.5642$ is the turning point. When the ratio between applied cyclic mechanical stress and reference cyclic mechanical stress is less than 0.5642 , damage caused by fatigue is great than that of creep, but creep and fatigue are still competitive mechanism. With the increasing of applied cyclic mechanical stress, creep damage jumps up significantly, and overly exceeds the damage induced by fatigue. From Fig.12, we can see that, for $\frac{\sigma_{p}^{A}}{\sigma_{p 0}^{\Delta}}=0.5$, the numbers of cycles to failure are 26650 and 88970 due to fatigue and creep damage mechanism, respectively. When the ratio reaches 0.5642 , this number to failure driving by fatigue is same to that of creep at 20765. As the growth of applied cyclic mechanical stress, creep effect gives rise to dramatical structural failure, for predefined reference loading condition, failure induced by creep would happen after 41 cycles, in comparison with fatigue, that value is 6792 .

Considering practical running status, steam turbine rarely operates at the rotating speed in almost half of the reference rotating speed, as a low rotating speed of turbine is not able to generate enough power to drive the subsequent electric generator. According to the previous analysis, for the investigated structure under practical high rotating speed, creep mechanism is the primary damaging mechanism leading to structure failure.

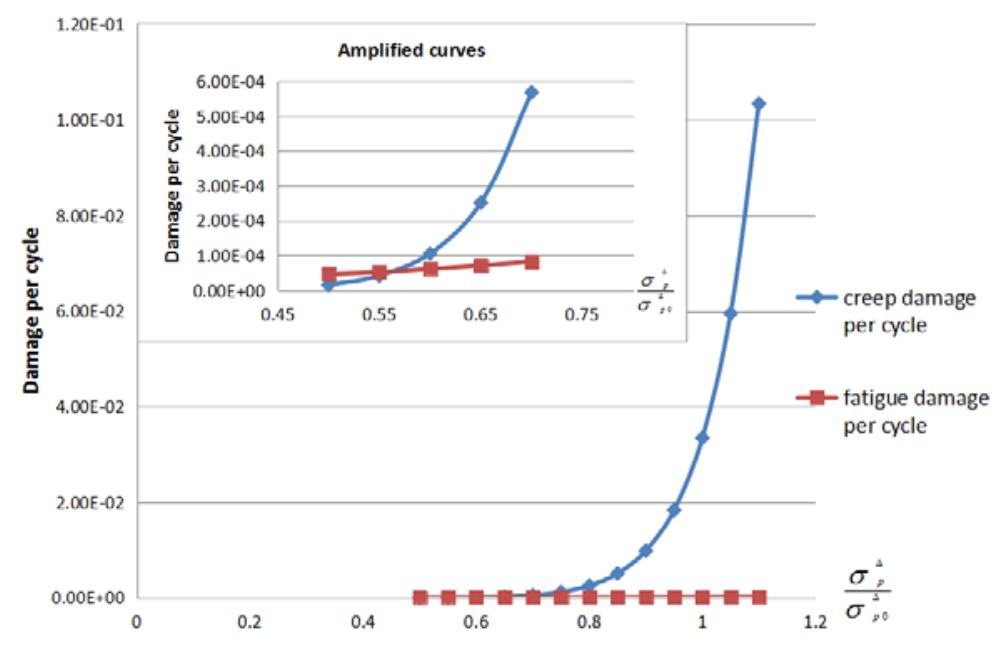

Fig.11. Creep and fatigue damage per cycle against the variation of cyclic mechanical stress 


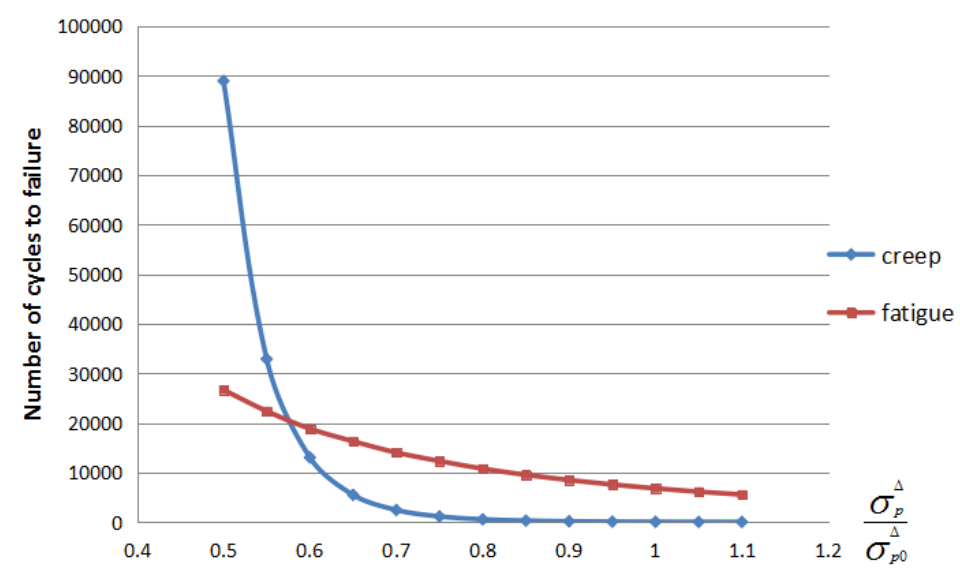

Fig.12 Number of cycles to failure induced by creep and fatigue damage mechanism against the variation of cyclic mechanical stress

Fig.13 to Fig.15 display the failure locations of the structure under $\frac{\sigma_{p}^{\Delta}}{\sigma_{p 0}^{\Delta}}=0.5, \frac{\sigma_{p}^{\Delta}}{\sigma_{p 0}^{\Delta}}=0.75$ and $\frac{\sigma_{p}^{\Delta}}{\sigma_{p 0}^{\Delta}}=1.05$, respectively. Generally, creep damage happens in quite small local range, comparing with that fatigue damage occurs in relatively global range. For $\frac{\sigma_{p}^{\Lambda}}{\sigma_{p 0}^{A}}=0.5$, where the integral failure is driven by fatigue effect, hence, the location where total damage initiates coincide with that of fatigue. For $\frac{\sigma_{p}^{\wedge}}{\sigma_{p 0}^{\wedge}}=0.75$ and $\frac{\sigma_{p}^{\wedge}}{\sigma_{p 0}^{\wedge}}=1.05$, the contours of total damage coincide with that of creep, which means the creep is the primary failure mechanism in those cases.

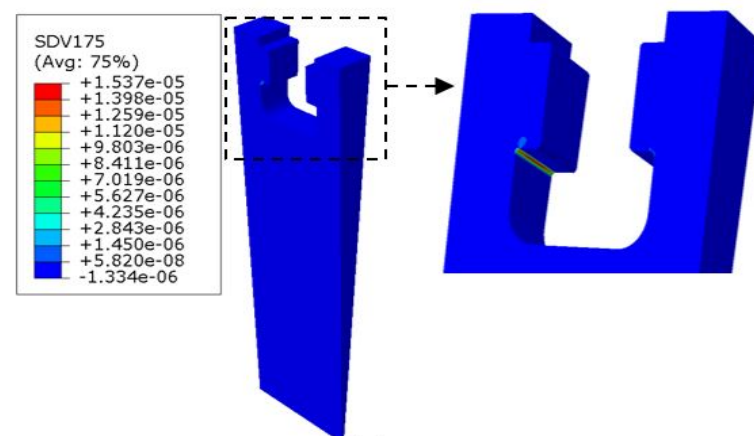

(a)

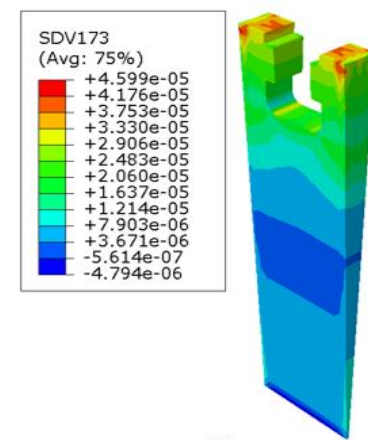

(b)

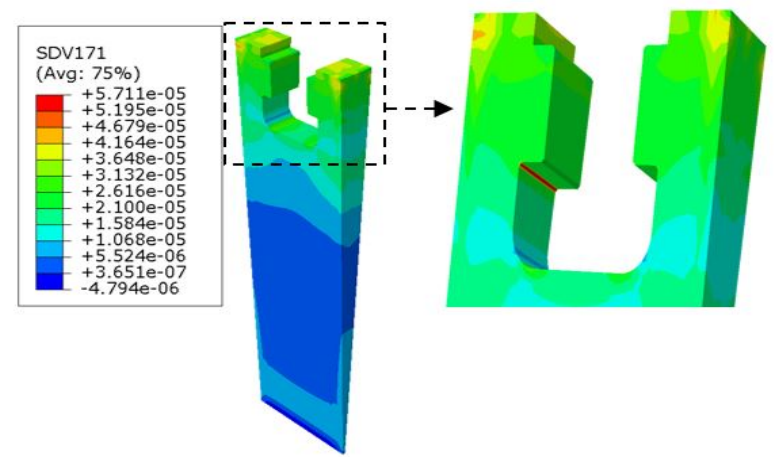

(c)

Fig.13. Contours of failure locations caused by (a) creep damage (b) fatigue damage (c) total damage under $\frac{\sigma_{p}^{\Delta}}{\sigma_{p 0}^{\Delta}}=0.5$ 


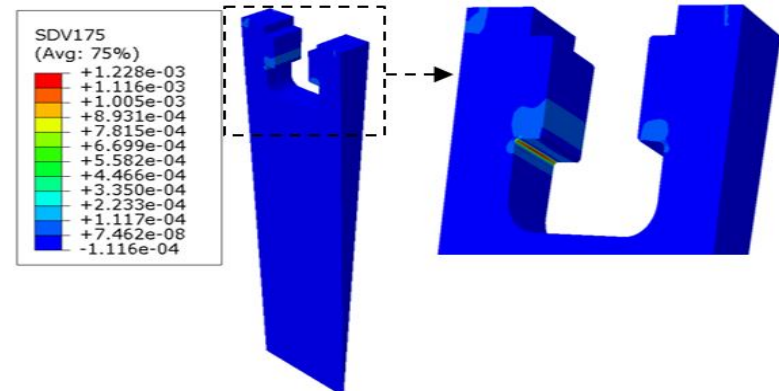

(a)

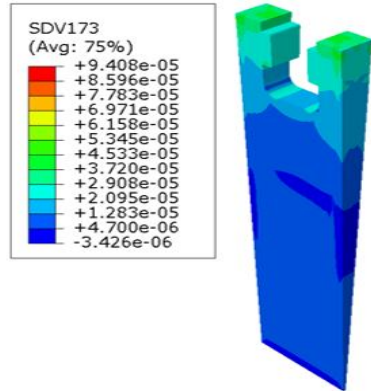

(b)

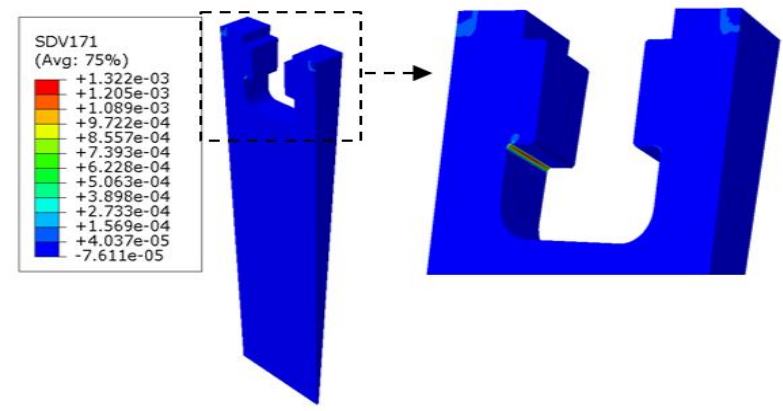

(c)

Fig.14. Contours of failure locations caused by (a) creep damage (b) fatigue damage (c) total damage under $\frac{\sigma_{p}^{\Delta}}{\sigma_{p 0}^{\Delta}}=0.75$

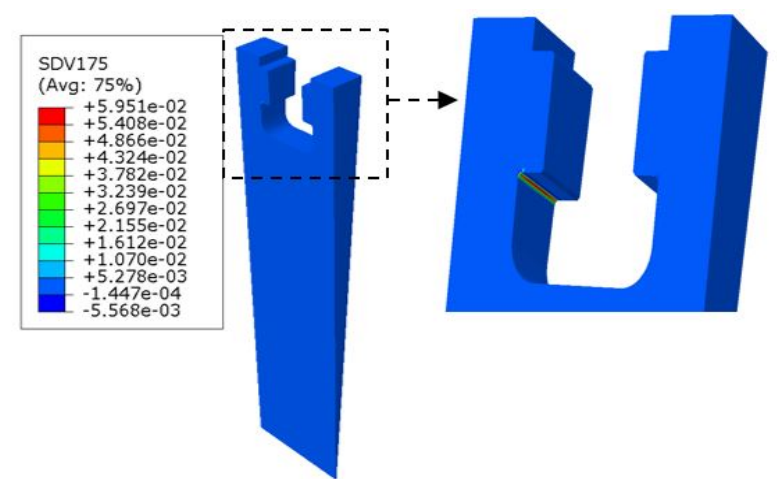

(a)
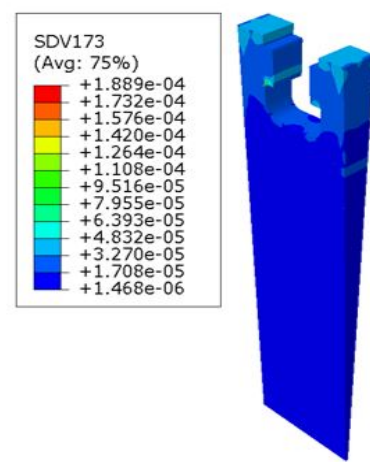

(b)

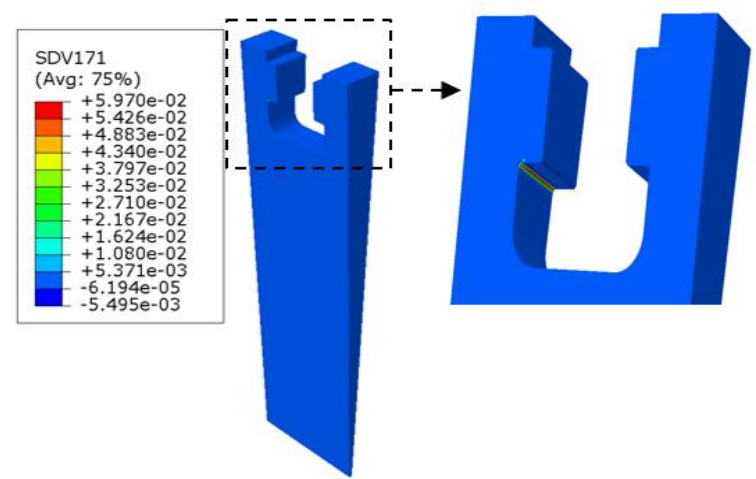

(c)

Fig.15. Contours of failure locations caused by (a) creep damage (b) fatigue damage (c) total damage under $\frac{\sigma_{p}^{\Delta}}{\sigma_{p 0}^{\Delta}}=1.05$ 


\section{Creep-rupture analyses}

In terms of previous creep-fatigue analyses, we can clearly see that creep is the primary factor leading to the failure of the steam rotor under long-term high temperature operation. Hence, the creep rupture analyses and the marines of creep rupture for the rotor are crucial to be investigated so as to prevent the structure from rapid destruction. A newly raised creep rupture assessment method under the Linear Matching Method framework has been proved [26] that is capable of evaluating the creep rupture limit through an extended shakedown analysis by employing the revised yield stress, where the revised yield stress is determined by the minimum of the yield stress of the material and the individual creep rupture stress at integration point.

\subsection{The creep rupture curves of the steam turbine rotor subjected to cyclic mechanical-thermal stress}

Fig.16 exhibits the creep rupture limit of rotor under cyclic thermal-mechanical load for desired creep rupture time by using the interpolated creep rupture experimental data, where the cyclic thermal-mechanical loads vary out-of-phase based on the practical reference load condition. In order to provide a benchmark to estimate the reasonable cyclic loading conditions for creep rupture assessment of steam turbine rotor, a shakedown limit interaction curve was calculated as given in Fig.16 through the adoption of the LMM shakedown analysis, which has been verified in [33]. The non-dimensional value of X-coordinate in Fig.16 represents the ratio of the applied cyclic mechanical stress with the reference cyclic mechanical stress, where $\frac{\sigma_{p}^{\Delta}}{\sigma_{p 0}^{\Delta}}=1$ corresponds to the current practical operation mechanical load. The non-dimensional value of Y-coordinate means the ratio of the applied cyclic thermal stress with the reference cyclic thermal stress, where $\frac{\sigma_{\theta}^{\Delta}}{\sigma_{\theta 0}^{\Delta}}=1$ represents the current practical operation thermal load.

By contrasting shakedown limit boundary with creep rupture curves, it is evident that the permissible loading condition of creep rupture mechanism for $3 \mathrm{kh}$ is harsher than that of shakedown failure, and creep rupture limits under longer desired time are sharply below shakedown limit. Thus, for rotor operating under high temperature, creep behaviour tremendously affects structural operating state and deserve more attention. It is worth noting that creep rupture limit curves obtained for 10khrs, 80khrs and 300khrs are almost coincident, which means the permissible loading ranges are nearly consistent for desired rupture time greater than 10khrs. Fig.17 leaves convergence plot of creep rupture limit for the steam turbine rotor subjected to cyclic thermal-mechanical load at rupture time equal to $10 \mathrm{khrs}, 80 \mathrm{khrs}$ and $300 \mathrm{khrs}$, from which we can see the calculated creep rupture limit multipliers of the three desired rupture time fluctuate intensely even after many increments. But they eventually reach almost the same value, which results in obtaining the nearly same permissible loading range. The underlying reason for this phenomenon is that, as the growth of desired rupture time from 10khrs to 300khrs, the expected rupture stress is assumed to decrease, which means the creep rupture multiplier calculated by the LMM is supposed to reduce. The applied temperature field of the structure in iterative process is positively related with the obtained creep rupture multiplier, so in this case, the applied temperature field is declining with the reduced creep rupture multiplier. As we introduced in section 2, the revised yield stress, which is minimum value of the yield stress of the material and the individual creep rupture stress at each integration point, is supposed to increase due to decreased temperature field. This in turn gives the structure more capacity to 
withstand greater loading. Finally, this balance mechanism produces so closed rupture curves for desired rupture time greater than $10 \mathrm{khrs}$.

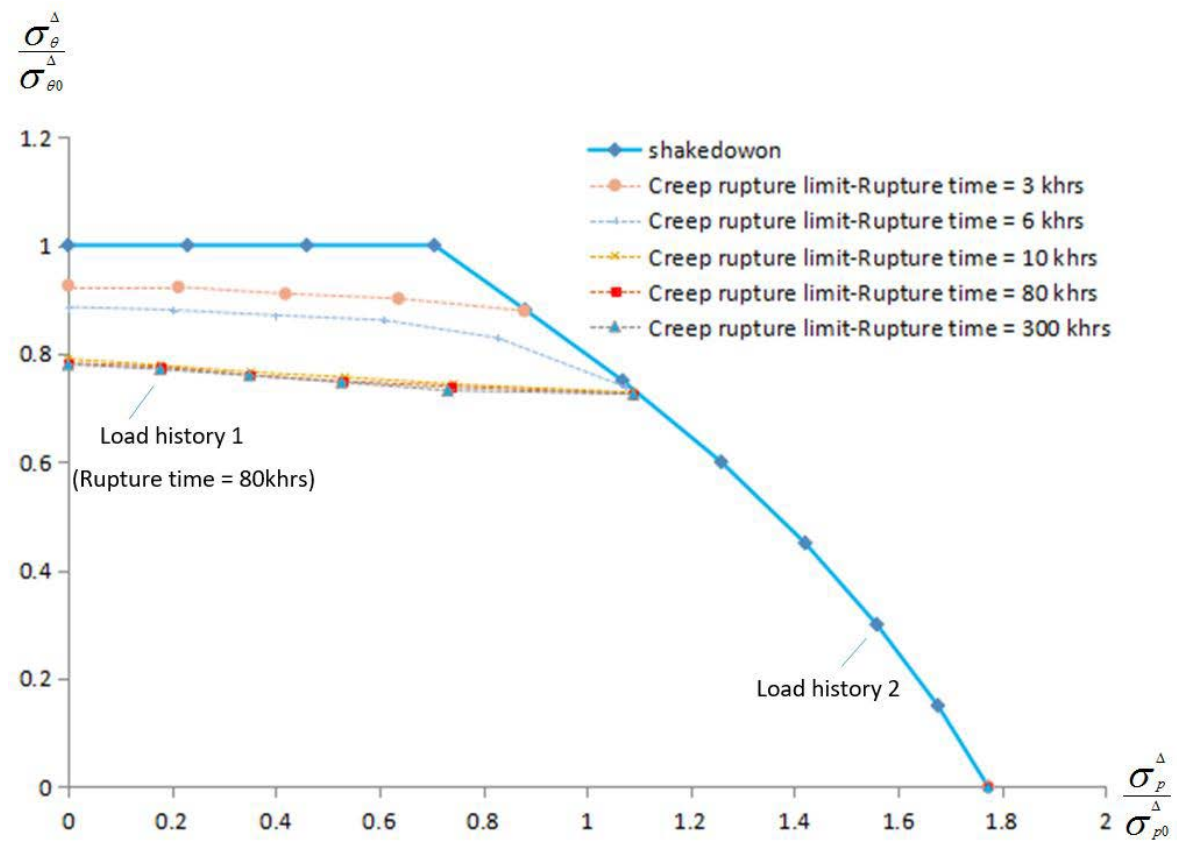

Fig.16. Creep rupture limit diagram for steam turbine rotor under cyclic mechanical load and cyclic thermal load for different time to rupture

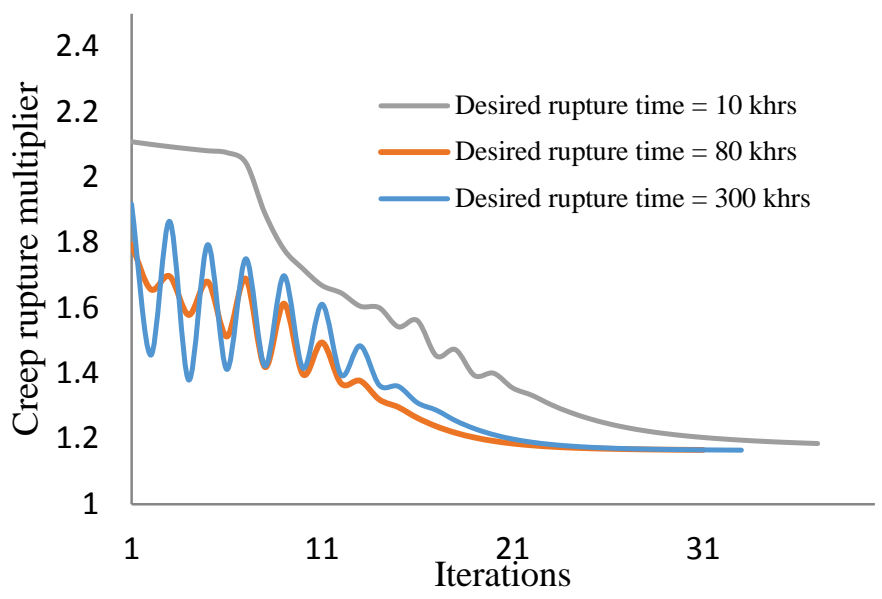

Fig.17. Convergence plot of creep rupture limit for the steam turbine rotor subjected to cyclic mechanical-thermal load at rupture time equal to $10 \mathrm{khrs}, 80 \mathrm{khrs}$ and $300 \mathrm{khrs}$

For creep rupture limit calculation of each single desired rupture time, the convergence issue shows the similar balance mechanism. Fig.18 displays the convergence curves of temperature and revised yield stress at 10khrs, 80khrs and 300khrs rupture time respectively, where the temperature positively correlates with the creep rupture multiplier and the revised yield stress negatively correlates with the creep rupture multiplier. During the progressive iterative analysis, the convergence algorithm is seeking to reduce the creep rupture multiplier at one iteration, then the applied temperature will decrease which produces the increasing revised yield stress. This in turn leads to the growth of creep rupture limit multiplier in the next iteration. This balance mechanism inevitably enhances the oscillation of the creep limit multiplier, as is shown in Fig 18. For figuring convergence 
issue out, in each iterative analysis, the mean of creep rupture limit multipliers of the last two iterations is applied to produce a new scaling factor, which will be used for scaling the temperature and attached thermal stress field. In Fig.18, we can observe that all obviously oscillating behaviors of creep rupture limit multiplier, temperature and revised yield stress occur before the first 20 iterations, and these parameters gradually converge after 20 iterations. Fig.19 (a) gives the distribution of the strain under loading history 1(load history 1 in Fig.16), form where we notice that the strain happens in global range as the cyclic thermal load is the primary effective load. Fig.19 (b) shows us the contours of the maximum locations of stain subjected to loading history 2 (load history 2 in Fig.16), where the primary strain occurs at the acting region of the cyclic mechanical load as the cyclic mechanical load contributes to the main part of current loading history.

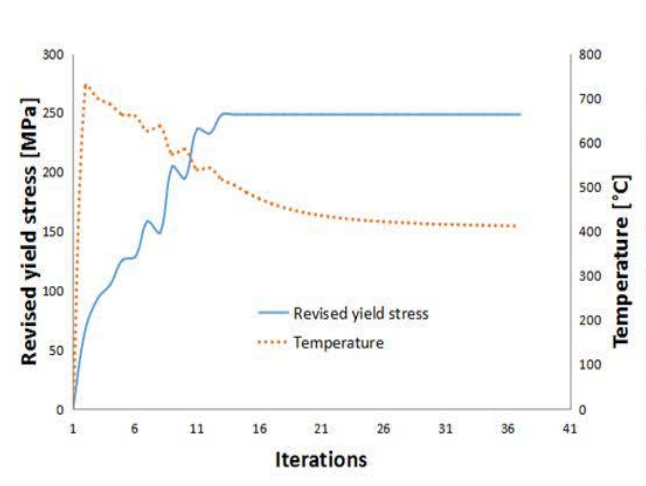

(a)

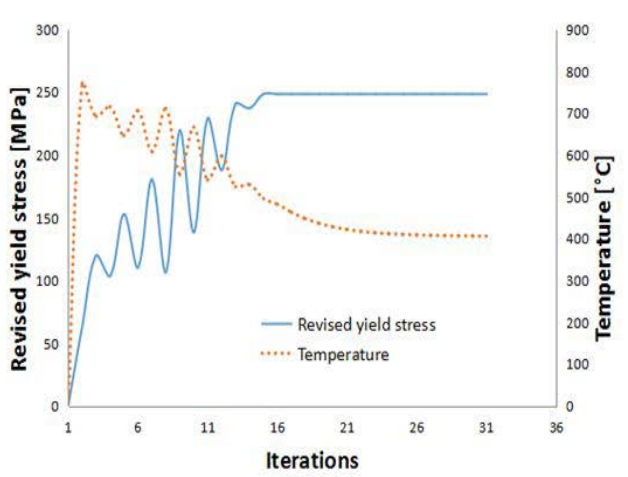

(b)

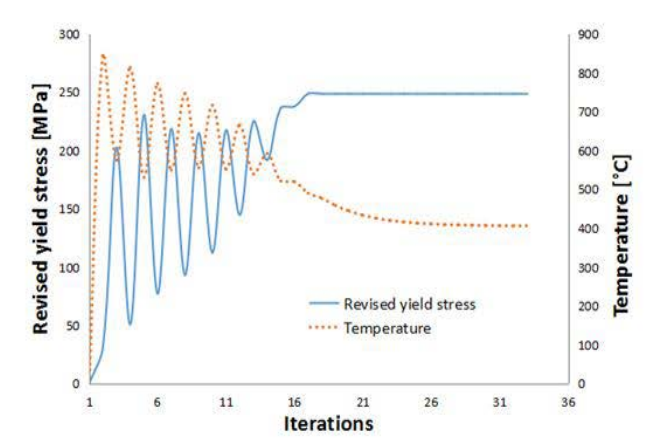

(c)

Fig.18. Convergence of the maximum temperature, revised yield stress (a) $10 \mathrm{khrs}$ (b) $80 \mathrm{khrs}$ (c) 300khrs

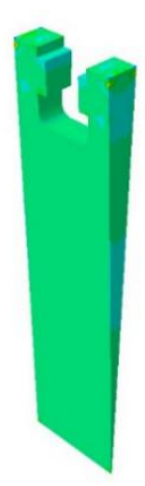

(a)

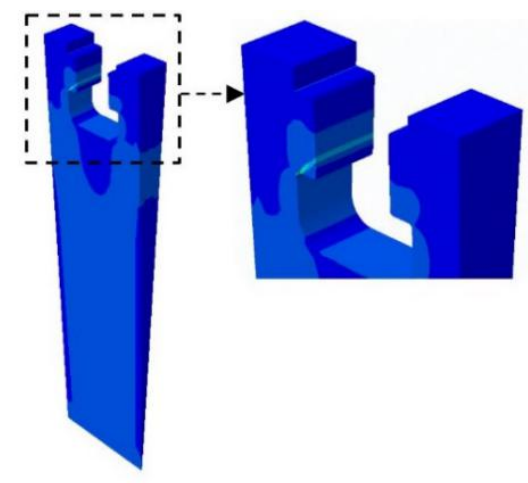

(b)

Fig.19 Contour plots of maximum locations of strain corresponding to loading histories (a) Load history 1 (b) Load history 2 
5.2 The creep rupture curves of the steam turbine rotor subjected to cyclic thermal-mechanical stress to withstand constant mechanical stress

We calculate different combinations of cyclic thermal-mechanical load and constant mechanical load, then plot the shakedown boundary, ratchetting boundary and creep rupture curves with varying desired rupture time for steam turbine rotor in Fig.20. The arbitrary applied constant mechanical load is normalized with respect to the reference constant mechanical load $\sigma_{P 0}$ in the X-axis, at which point $\mathrm{A}$ is denoted as the limit load of constant mechanical load, and the applied cyclic thermal-mechanical load in the Y-axis is normalized by referenced cyclic load $\sigma_{P \theta 0}^{\Delta}$. In Fig.20, we can clearly observe that, for rupture time greater than $10 \mathrm{khrs}$, the creep rupture curves are greatly adjacent, which is caused by the same balance mechanism discussed in previous section. Fig.21 presents the distribution of strain under loading history B and C, with the growing of the proportion of the constant mechanical load in total loading history, the failure turns to follow $45^{\circ}$ around cut off along the force direction corresponding with the acting area of constant mechanical load.

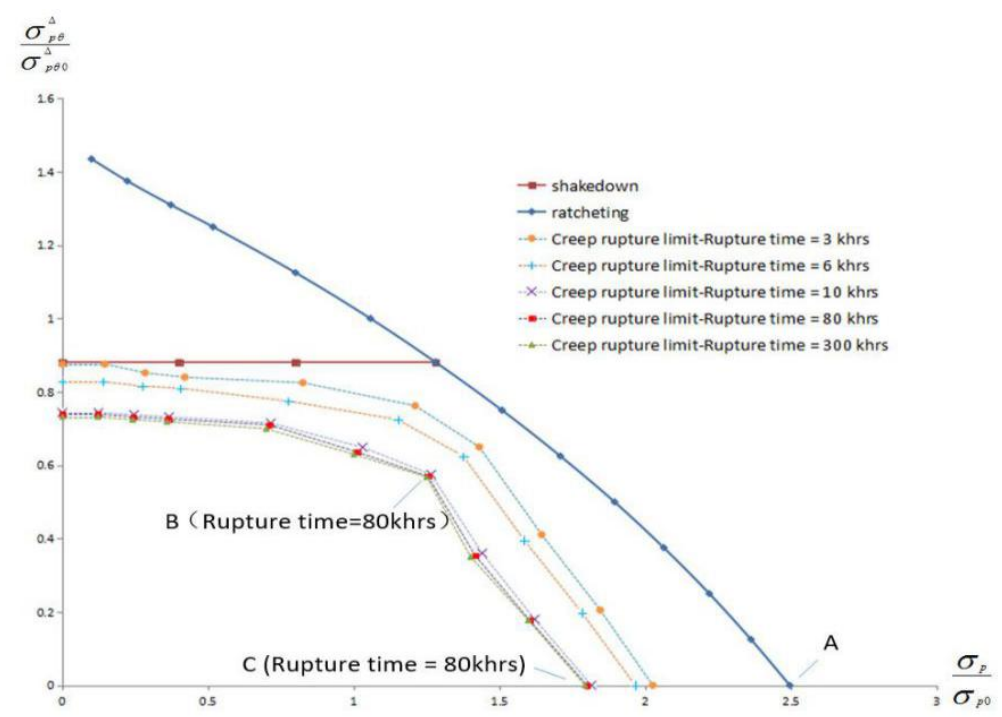

Fig.20. Creep rupture limit diagram for steam turbine rotor under cyclic thermal-mechanical load and constant mechanical load for different time to rupture

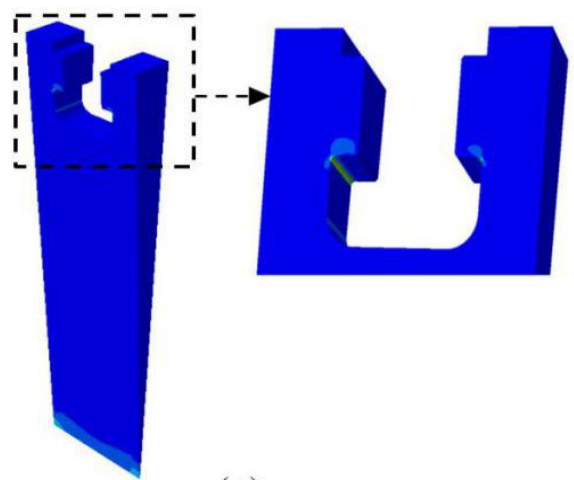

(a)

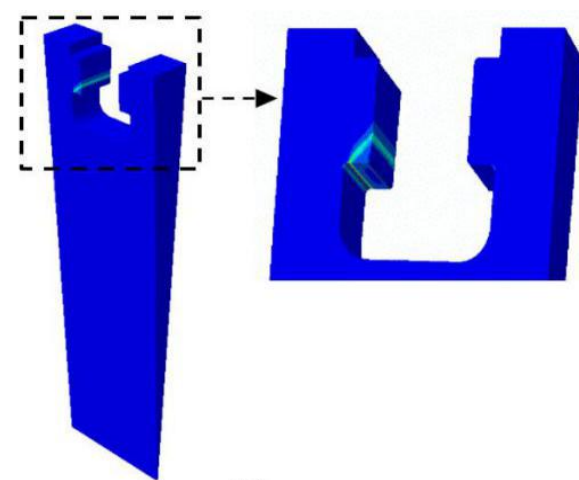

(b)

Fig.21. Contour plots of maximum locations of strain corresponding to loading histories (a) Load point B (b) Load point C 
Fig.20 provides the creep rupture limit as the capacity of the structure subjected to a predefined cyclic thermalmechanical load to accommodate an additional constant mechanical load, where the applied cyclic thermalmechanical load vary strictly in-phase based upon the predefined load cycle. While the creep rupture limit given in previous creep rupture analysis (Fig.16) is the limit of the structure subjected to cyclic thermal-mechanical load that vary out-of-phase throughout the respective reference loading history. Hence, the LMM provides the efficient method to calculate creep rupture limit of the structure with respect to in-phase and out-of-phase variations between the cyclic mechanical and thermal loads.

\section{Conclusion}

In this study, creep-fatigue analyses and creep rupture assessment have been made for the steam turbine rotor under alternating thermal-mechanical load by means of the LMM. Factors including dwell time, rotating speed of steam turbine rotor, which affect creep-fatigue behaviors of the structure are evaluated. For predefined reference loading condition, where dwell time lasts 2769h, local elements are about to fail after 38 cycles, which is induced by creep-fatigue interaction effect, with a predicted life of 41 and 6792 cycles for creep damage and fatigue damage respectively. By analyzing dwell time from $249 \mathrm{~h}$ to $4209 \mathrm{~h}$, we observe that damage caused by creep greatly exceed that of fatigue by at least 43 times. It means that creep is the dominant factor leading to structural failure comparing with fatigue behaviour for steam turbine rotor based on reference alternating loading condition. On the other hand, it can be observed from the contour plots that the creep damage happens in relatively local groove zone which is the significant concentration region of mechanical stress. In comparison with fatigue damage caused by the combination of cyclic thermal loads, the corresponding damage location emerges in the global area.

The applied cyclic mechanical load $\sigma_{p}^{\Delta}$, as the crucial load for creep behaviour, can be adjusted corresponding to rotating speed of the structure. When the ratio between applied cyclic mechanical load and predefined cyclic mechanical load $\frac{\sigma_{p}^{\Delta}}{\sigma_{p 0}^{\Delta}}$ is greater than 0.5642 , damage induced by creep exceeds that of fatigue, and the result is adverse when $\frac{\sigma_{p}^{\Delta}}{\sigma_{p 0}^{\Delta}}<0.5642$ happens. For practical operation, not enough power could be generated as the $\frac{\sigma_{p}^{\Delta}}{\sigma_{p 0}^{\Delta}}$ is less than 0.5642. Therefore for designing of the same structure, more attention should be paid on creep damage mechanism. Further creep rupture analyses give the creep rupture curves for various desired rupture time of the structure in two ways, one is the limits of the structure to accommodate out of phase varying cyclic thermalmechanical load and the other one is the capacity of the steam turbine rotor subjected to in phase varying practical operation load cycle to withstand an additional constant load. By contrasting creep rupture boundary with cyclic plasticity failure boundary of the structure, it is evident that creep behaviour dramatically reduces the permissible loading range of rotor. We also notice that the creep rupture curves are going to coincide with the increasing of desired rupture time, which is caused by competitive balance mechanism of revised yield stress. These creep failure diagrams can be further used to evaluate the reliability of high-temperature steam turbine rotor at the first few steps of the entire structural integrity assessment procedure and to avoid the rapid structural failure. 
This paper provides that, comparing with fatigue failure behaviour, damage induced by creep mechanism will bring more threats to structural integrity of steam turbine rotor in most of practical operation conditions, and it is meaningful to establish creep rupture margins so as to prevent structure from rapid destruction. Also this work demonstrates that the LMM is capable of simulating a wider range of loading circumstances under hightemperature conditions, including out-of-phase and in-phase variations between the cyclic mechanical and thermal loads, and providing accurate creep-fatigue damage and creep rupture limits with high computational efficiency.

\section{Acknowledgments}

The authors gratefully acknowledge the supports from the National Natural Science Foundation of China (51828501), Fundamental Research Funds for the Central Universities (No.N18234009), University of Strathclyde and East China University of Science and Technology during the course of this work.

\section{References}

[1] A.R., Junaidi, 2013. Design optimization and analysis of a steam turbine rotor grooves. Losrjournals Org, 2013, 8(6): 66-72.

[2] B.S., Yang, S.P., Choi, Y.C., Kim, 2005. Vibration reduction optimum design of a steam-turbine rotorbearing system using a hybrid genetic algorithm. Structural \& Multidisciplinary Optimization, 2005,30(1): 4353.

[3] B.K., Choi, B.S., Yang, 2001. Optimal design of rotor-bearing systems using immune-genetic algorithm. Journal of Vibration \& Acoustics, 2001, 123(3): 398-401.

[4] Ulrich, E.Klotz, 2008. Martensitic - austenitic 9 - 12\% Cr steels-Alloy design, microstructural stability and mechanical properties. Materials Science and Engineering: A, 476, pp 186-194

[5] J., Dong, Y., He, M., Kim, K., Shin, 2013. Effect of creep stress on the microstructure of 9-12\% Cr steel for rotor materials. Microscopy \& Microanalysis the Official Journal of Microscopy Society of America Microbeam Analysis Society Microscopical Society of Canada, 2013, 19 Suppl 5(S5):95

[6] D. Miller, R. Priest and E. Ellison. A review of material response and life prediction techniques under fatigue-creep loading conditions. High-temperature materials and processes, 6(3-4): 155\{194, 1984.

[7] D. Hu, Q. Ma, L. Shang, Y. Gao, R. Wang. Creep-fatigue behavior of turbine disc of superalloy GH720Li at $650^{\circ} \mathrm{C}$ and probabilistic creep-fatigue modeling. Materials Science and Engineering: A, 2016, 670:17-25.

[8] D. Hu, R. Wang, G. Hou. Life assessment of turbine components through experimental and numerical investigations. Journal of Pressure Vessel Technology, 2013, 135:024502.

[9] R. Hales. A quantitative metallographic assessment of structural degradation of type 316 stainless steel during creep-fatigue. Fatigue \& Fracture of Engineering Materials \&Structures, 3(4): 339-356, 1980.

[10] W. Plumbridge. Metallography of high temperature fatigue, pages 177 \{228. Springer, 1987. 
[11] Chaboche J., 1984. Anisotropic creep damage in the framework of continuum damage mechanics. Nuclear Engineering\&Design. 79, 309-319.

[12] Hyde, T., Xia L., Becker, A., 1996. Prediction of creep failure in aeroengine materials under multi-axial stress states. International Journal of Mechanical Science, 38, 385-403.

[13] Kachanov, L.M., 1999. Rupture time under creep conditions. International Journal of Fracture, 97, 11-18.

[14] Ainsworth, R., 2003. R5: Assessment Procedure for the High Temperature Response of Structures. British Energy Generation Ltd 3.

[15] W Wang, P Buhl, A Klenk, Y Liu, 2016. Influence of high-temperature dwell time on creep-fatigue behavior in a 1000 MW steam turbine rotor. Engineering Fracture Mechanics, 2016, 166: 1-22.

[16] Jing J, Meng G, 2005. A continuum damage mechanics model on creep rupture life assessment of a steam turbine rotor. Journal of Engineering for Gas Turbines and Power, 2005, 128(1), 173-177.

[17] Jing J, Meng G, Sun Y, Xia S, 2003. An effective continuum damage mechanics model for creep-fatigue life assessment of a steam turbine rotor. International Journal of Pressure Vessels and Piping, 2003, 80(6), 389396

[18] Ponter ARS, Chen HF, 2001. A minimum theorem for cyclic load in excess of shakedown, with application to the evaluation of a ratchet limit. European Journal of Mechanics - A/Solids, 2001, 20(4), 539-553.

[19] Chen H.F., Ponter A.R.S., 2001. A method for evaluation of a ratchet limit and the amplitude of plastic strain for bodies subjected to cyclic loading. European Journal of Mechanics - A/Solids, 2001, 20(4), 553-571..

[20] Chen H, Chen W, Ure J, 2014. A direct method on the evaluation of cyclic steady state of structures with creep effect. Journal of Pressure Vessel and Technology, 2014, 136(6), 061404.

[21] Chen H, Ponter AR, 2006. Linear matching method on the evaluation of plastic and creep behaviours for bodies subjected to cyclic thermal and mechanical loading. International Journal for Numerical Methods in Engineering, 2006, 68(1), 13-32.

[22] Barbera D., Chen H.F., 2015. Creep rupture assessment by a robust creep data interpolation using the Linear Matching Method. European Journal of Mechanics A/Solids, 54(2015), 267-279.

[23] Chen H.F., Ponter A.R.S., Anisworth R.A., 2006. The linear matching method applied to high temperature life integrity of structures. Part 1 . Assessments involving constant residual stress fields. International Journal of Pressure Vessels and Piping, 83, 123-135.

[24] Chen H, Chen W, Ure J. A direct method on the evaluation of cyclic steady state of structures with creep effect. Journal of Pressure Vessel Technology, 2014; 136(6):061404

[25] Chen H., Engelhardt M.J., Ponter A.R.S., 2003. Linear matching method for creep rupture assessment. International Journal of Pressure Vessels and Piping, 80, 213-220. 
[26] Barbera D., Chen H., 2015. Creep rupture assessment by a robust creep data interpolation using the Linear Matching Method. European Journal of Mechanics A/Solids, 2015, 54:267-279.

[27] Larson, F.R., Miller, J., 1952. A time-temperature relationship for rupture and creep stresses. Trans. ASME July 765-775.

[28] Manson, S.S., Haferd, A.M., 1953. A linear Time-Temperature Relation for Extrapolation of Creep and Stress - Rupture Data, Other information: Orig Receipt Data: 31-DEC-53. Lewis Flight Propulsion Lab., NACA. P. Medium: X; Size : Page: 49.

[29] Mendelson, A., Roberts Jr., E., Manson. S., 1965. Optimization of Time-temperature Parameters for Creep and Stress Rupture, with Application to Data from German Cooperative Long-time Creep Program. DTIC Document.

[30] Pink, E., 1994. Physical significance and reliability of Larson-Miller and Manson-Haferd parameters. Master. Sci. Technol. 10. 340-346.

[31] Whittaker, M.T., Evans, M., Wilshire, B., 2012. Long-term creep data prediction for type 316H stainless steel. Master. Sci. Eng. A 552, 145-150.

[32] Hibbitt, H., Karlsson, B., Sorensen, P., 2012. ABAQUS Theory Manual, Version 6.12. Pawtucket, Rhode Island, USA.

[33] Zhu X.C., Chen H.F., Xuan F.Z., Chen X.H., 2017. Cyclic plasticity behaviors of steam turbine rotor subjected to cyclic thermal and mechanical loads. European Journal of Mechanics A/Solids, 2017, 66:243-255.

[34] National Institution for Materials Science, Materials Database, Fatigue Data Sheet. 